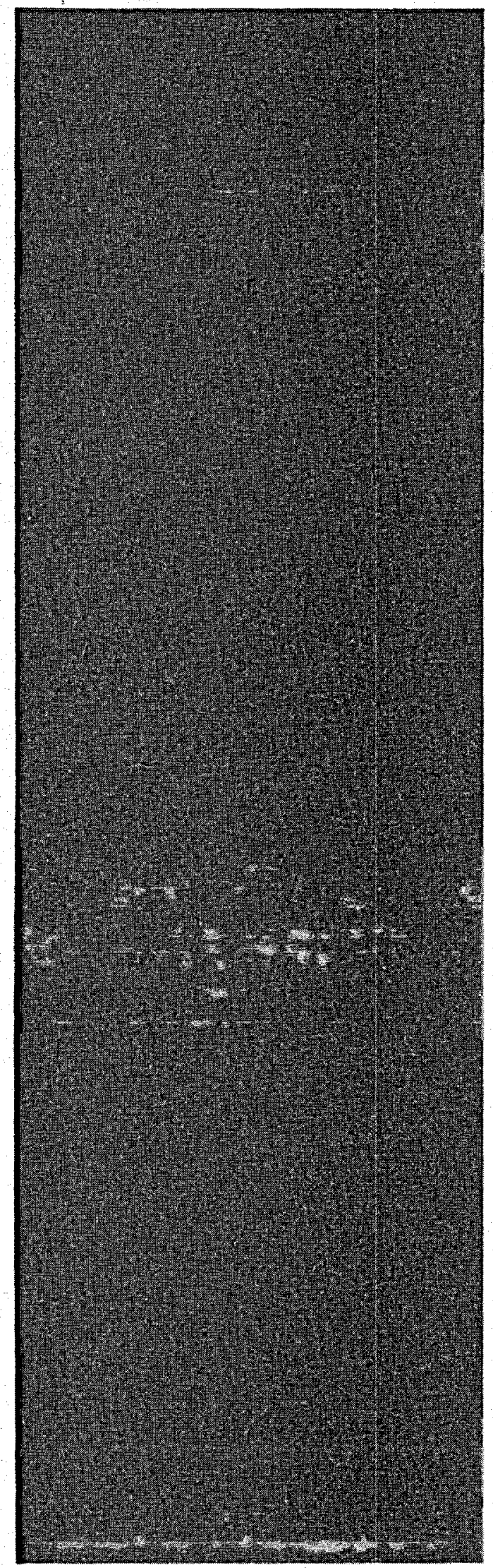

\title{
JAN 091989
}

Field Procedures Manual:

\section{INYO-4, Long Valley Caldera, California}

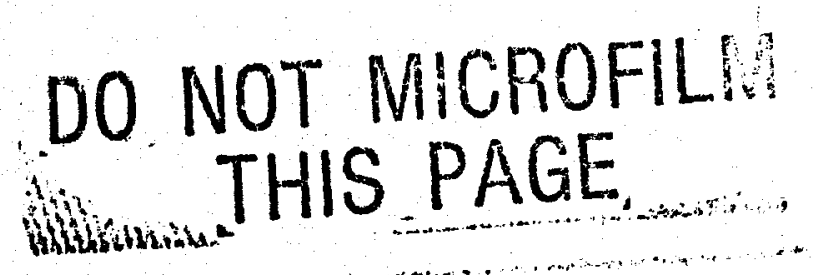

\section{LOS Allamos}

Los Alamos National Laboratory is operated by the University of California for the United States Department of Energy under contract W-7405-ENG-36.

\section{MASTER}


This work was supported by the U.S. Department of Energy, Office of Basic Energy Sciences.

An Affirmative Action/Equal Opportunity Employer

\section{DO NOT MICROFILIH Wh.... THIS PAGE}

This report was prepared as an account of work sponsored by an agency of the United States Government. Neither the United States Government nor any agency thereof, nor any of their employees, makes any warranty, express or implied, or assumes any legal liability or responsibility for the accuracy, completeness, or usefulness of any information, apparatus, product, or process disclosed, or represents that its use would not infringe privately owned rights. Reference herein to any specific commercial product, process, or service by trade name, trademark, manufacturer, or otherwise, does not necessarily constitute or imply its endorsement, recommendation, or favoring by the United States Government or any agency thereof. The views and opinions of authors expressed herein do not necessarily state or reflect those of the United States Government or any agency thereof. 


\section{DISCLAIMER}

This report was prepared as an account of work sponsored by an agency of the United States Government. Neither the United States Government nor any agency Thereof, nor any of their employees, makes any warranty, express or implied, or assumes any legal liability or responsibility for the accuracy, completeness, or usefulness of any information, apparatus, product, or process disclosed, or represents that its use would not infringe privately owned rights. Reference herein to any specific commercial product, process, or service by trade name, trademark, manufacturer, or otherwise does not necessarily constitute or imply its endorsement, recommendation, or favoring by the United States Government or any agency thereof. The views and opinions of authors expressed herein do not necessarily state or reflect those of the United States Government or any agency thereof. 


\section{DISCLAIMER}

Portions of this document may be illegible in electronic image products. Images are produced from the best available original document. 


\section{I.A--11477-OBES}

\section{DE89 005214}

Field Procedures Manual:

INYO-4, Long Valley Caldera, California

\section{Sue Goff}

\section{DISCLAIMER}

This report was prepared as an account of work sponsored by an agency of the United States Government. Neither the United States Government nor any agency thereof, nor any of their employees, makes any warranty, express or implied, or assumes any legal liability or responsibility for the accuracy, completeness, or usefulness of any information, apparatus, product, or process disclosed, or represents that its use would not infringe privately owned rights. Reference herein to any specific commercial product, process, or service by trade name, trademark, manufacturer, or otherwise does not necessarily constitute or imply its endorsement, recommendation, or favoring by the United States Government or any agency thereof. The views and opinions of authors expressed herein do not necessarily state or reflect those of the United States Government or any agency thereof. 



\section{FIELD PROCEDURES MANUAL: \\ INYO-4, LONG VALLEY CALDERA, CALIFORNIA}

by

Sue Goff

ABSTRACT

This Field Procedures Manual is the comprehensive operations guide to be used to curate samples obtained from the INYO-4 site in the Long Valley Caldera, California. This site is a diamond drilling project in small-diameter holes that will produce continuous core. Fluid samples will also be of primary importance at this site. Detailed core and fluid handling procedures are therefore the major focus of this manual.

The manual provides a comprehensive operations guide for the well-site geoscientist working at the Department of Energy/Office of Basic Energy Sciences (DOE/OBES) Continental Scientific Drilling Program (CSDP)/Thermal Regimes drill sites. These procedures modify and improve those in previous DOE/OBES fleld manuals.

\section{SUMMARY OF DUTIES}

The primary responsibility of the well-site geoscientist assigned to the Office of Basic Energy Sciences/Continental Scientific Drilling Program (OBES/CSDP) sites is to provide continuous (24-hour-a-day) well-site coverage in support of drilling, coring, fluid sampling, and geophysical logging procedures. A geoscientist must be on location for all activities that are related to these operations. Other testing and drill hole operations may have to be supported on an "as needed" basis.

\section{DAILY ACTIVITY LOG}

A daily well-site activity log shall be kept on site as a narrative record of activities. All entries in the log must be clear and precise (and in indelible ink). The log is the primary record of well-site activity during a geoscientist's shift, and the geoscientist on the next shift will use it to 
become acquainted with previous activities. The initial entry should document the shift change. The following information should be recorded:

A. Rig shutdowns: record the time, reason, and depth. Enter the time when drilling resumes (with the date when applicable).

B. Borehole fluid circulation information, such as zones of lost circulation.

C. Changes in the drilling plan or the well-site procedures: document the time, date, reasons, and name of the person making the change.

D. Any information that the geoscientist feels may affect the completion of the drill hole or that is related to the drill hole.

E. Data or samples obtained or sought: record time, type, individual, and organization.

F. Interruptions in progress: record time, cause, etc.

G. Rig-ups of service company equipment: record type, objective, rig-downs, and success.

\section{COMMUNICATIONS PROCEDURES}

A. The geoscientist going off shift must tell the geoscientist coming on shift what occurred during the previous shift, must mention any changes in procedure or drilling plan for the new shift, and must relay any special instructions.

B. All changes in well-site procedures, core handling or sampling criteria, or approved revisions in drilling procedures should be communicated orally, recorded in the daily $\log$, and posted in a secure, obvious manner (i.e., bulletin board).

C. When necessary, the geoscientist on duty should contact the geoscientist going out to the well site to order supplies.

D. The geoscientist on duty should attempt to inform the geoscientist preparing to come on shift if, for some reason, he is not required on site.

E. The geoscientist on shift will participate in the daily on-site staff meetings.

\section{SAMPLE RECORDS}

On-site logs must be kept of sampling operations. A separate form will be used for each type of sample (core, water, bit cuttings, etc.). For many sites the core $\log$ (Fig. 1) will be the primary record. Forms should be self-explanatory and include all pertinent information; emphasis 


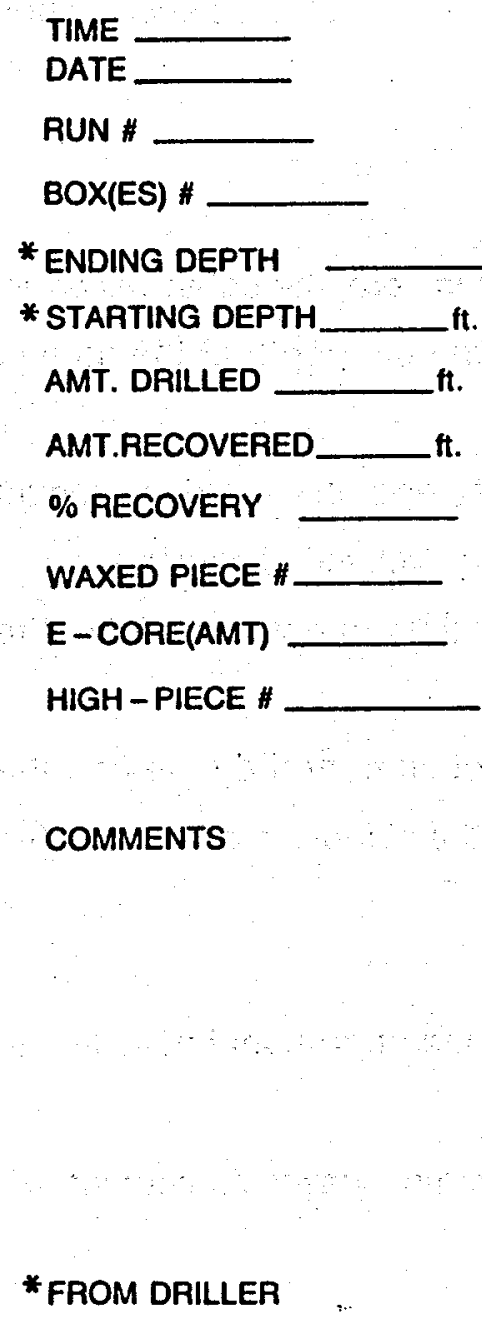

BOREHOLE fit. ft. ft. ft.

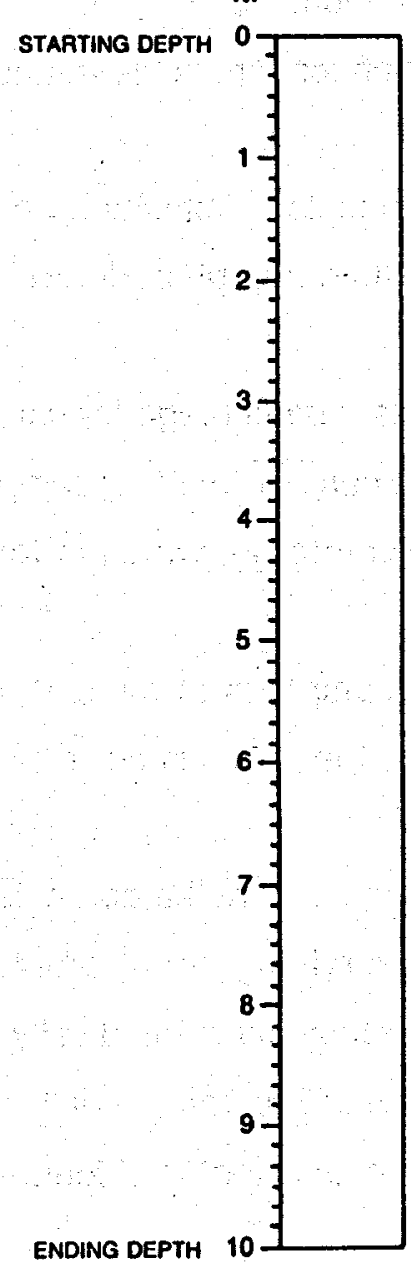

CORE LITHOLOGY

SIGNATURE

Fig. 1. Core log. 
should be placed on information that will be lost if it is not recorded at the time of sampling. These logs should be factual accounts, and any questionable entries should be noted as such. They should contain the following information:

A. Sequence number, which for core is the run number.

B. Sample number.

C. Depth from which the sample is obtained. Sometimes, as in core, the depth will be an interval. For surface fluid samples, depth is the bottom hole depth at the time of sampling.

D. Recovery, which means a percentage for core (i.e., percentage recovered vs amount cored) or a quantitative number for other sample types (e.g., volume of sample).

E. Sample description (lithology), which is to be brief and used only as an on-site reference.

F. Sample splits. If the sample is to be split at the site, document the type and the amount of the split, why the action is being taken, where the sample is going, and the requester's name.

Note: No sample splits shall be taken at the borehole site.

G. Comments. Record everything, from sample handling and operational activities to weather conditions, that may affect the quality of the data.

Note: All field measurements must conform to driller's format. In most cases conforming will mean taking measurements in tenths of feet.

\section{CORE HANDLING PROCEDURES}

The geoscientist shall be present when the core barrel is removed from the well. Core is measured by running a tape measure into the barrel before the core is removed and subtracting the unfilled space from the total length of the core barrel. Core is then placed in the core trough by the rig crew. Be sure that

- all pieces of core are in the proper sequence,

- all pieces of core are oriented in the proper direction, and

- the top of the run is indicated using a wooden block labeled "TOP."

If core needs to be washed, wash it while it is in the core trough. Mark individual pieces of core with a grease pencil or felt-tip marker using a straight, continuous line and include downhole arrows, the run number, and the piece number. Begin marking piece numbers with " 1 " on the first 
(top) piece, and mark pieces sequentially to the last (bottom) piece (Fig. 2). Mark any pieces of core that are as long or longer than the core width with a grease pencil or a felt-tip marker. Transfer core from the trough to a core box.

\section{BOXING AND LABELING CORE}

The drilling company will provide cardboard core boxes, which the geoscientist will number sequentially. The core should be boxed with the top of the run in the upper left corner and with core orientation maintained. If it is necessary to break a piece of core to fit it into the core box, the procedure on "Breaking and Renumbering Pieces of Core" (Section VII) should be followed. A complete core run may require more than one box, but sometimes several runs can be placed in the same sample box.

Place a run block (a wooden block wrapped with yellow tape) in the core box so that it precedes the first piece of core from an individual run (Fig. 2). Record the hole designation, run number, interval cored, the amount cored, and the amount recovered on the run block using an indelible felt-tip marker (Fig. 3). (An ending footage block should follow the last piece of core in the box.)

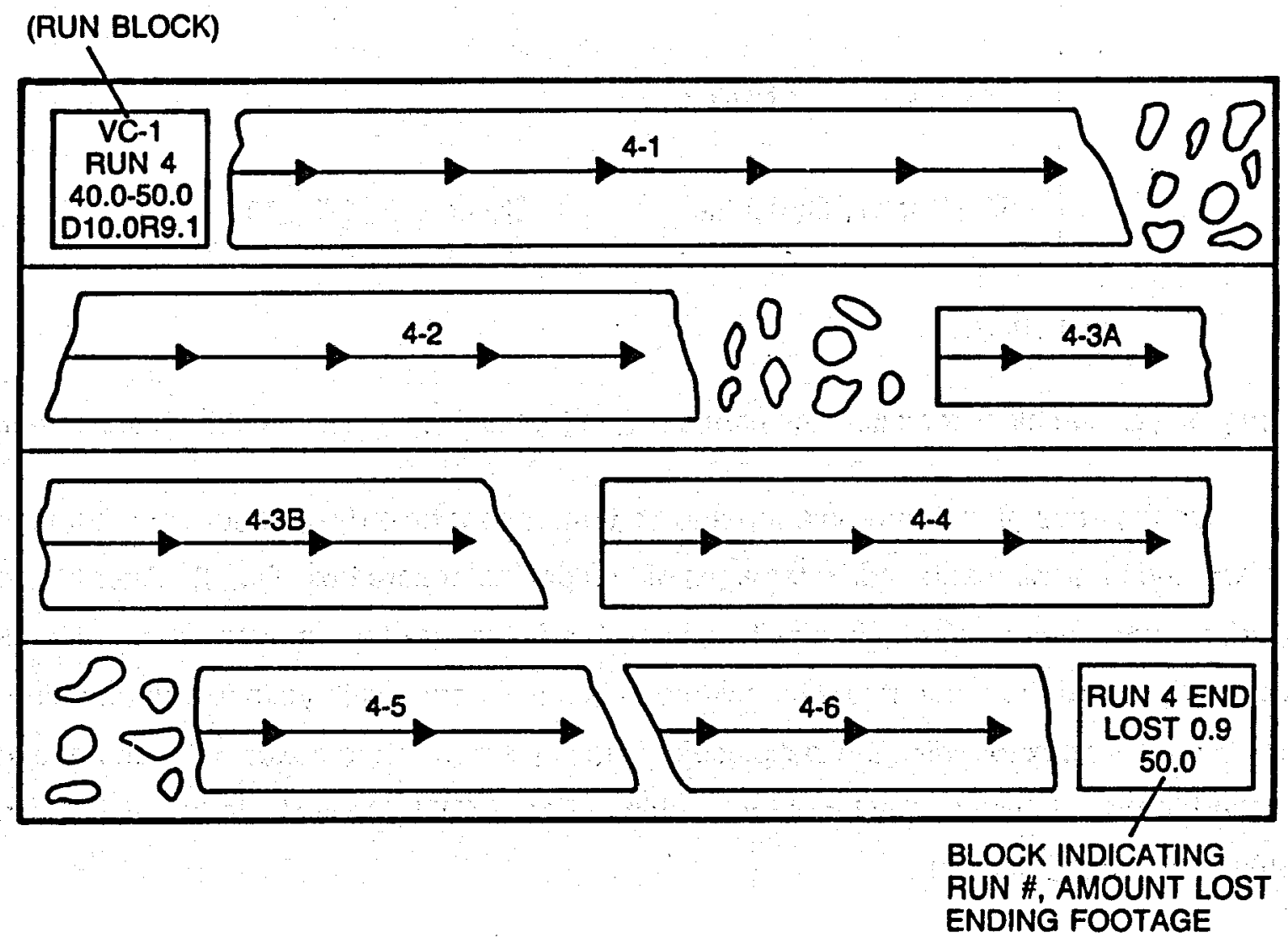

Fig. 2. Core box arrangement. 


\section{HOLE DESIGNATION}

CORE RUN NUMBER

INTERVAL CORED

\section{AMOUNT CORED AMOUNT. RECOVERED}

(a) Run block

(yellow-tape-wrapped wooden block--

precedes first piece of core in run).

\begin{tabular}{l} 
HOLE DESIGNATION (e.g., Valles Caldera 1) \\
BOX \# RUN \# \\
BEGINNING FOOTAGE $\quad$ ENDING FOOTAGE \\
\hline
\end{tabular}

(b) Labels.

Fig. 3. (a) Run block for inside the core box and (b) labels for the ends of the core boxes.

On the ends of the core box, top and bottom, record hole designation, box number, run number, and beginning and ending footages of that particular core box (Fig. 3). After the core is boxed, re-mark over any grease pencil labels with a felt-tip marker. If all the core drilled is not recovered, record the amount lost on a wooden block wrapped with yellow tape and place the block in the core box following the last piece of core in that run. Core boxes will then be ready for transport to the well-site facility for photographing. For INYO-4, the well-site facility is located in Mammoth Lakes, California. 


\section{BREAKING AND RENUMBERING PIECES OF CORE}

The geoscientist may have to break the core for boxing (Fig. 4). The resulting pieces will be renumbered with the run number and piece number, and the broken pieces will become, for example, 4-2A, 4-2B, etc., with alphabetical designations.

If the geoscientist breaks the core, that information should be recorded in the run description section of the field form (Fig. 1).

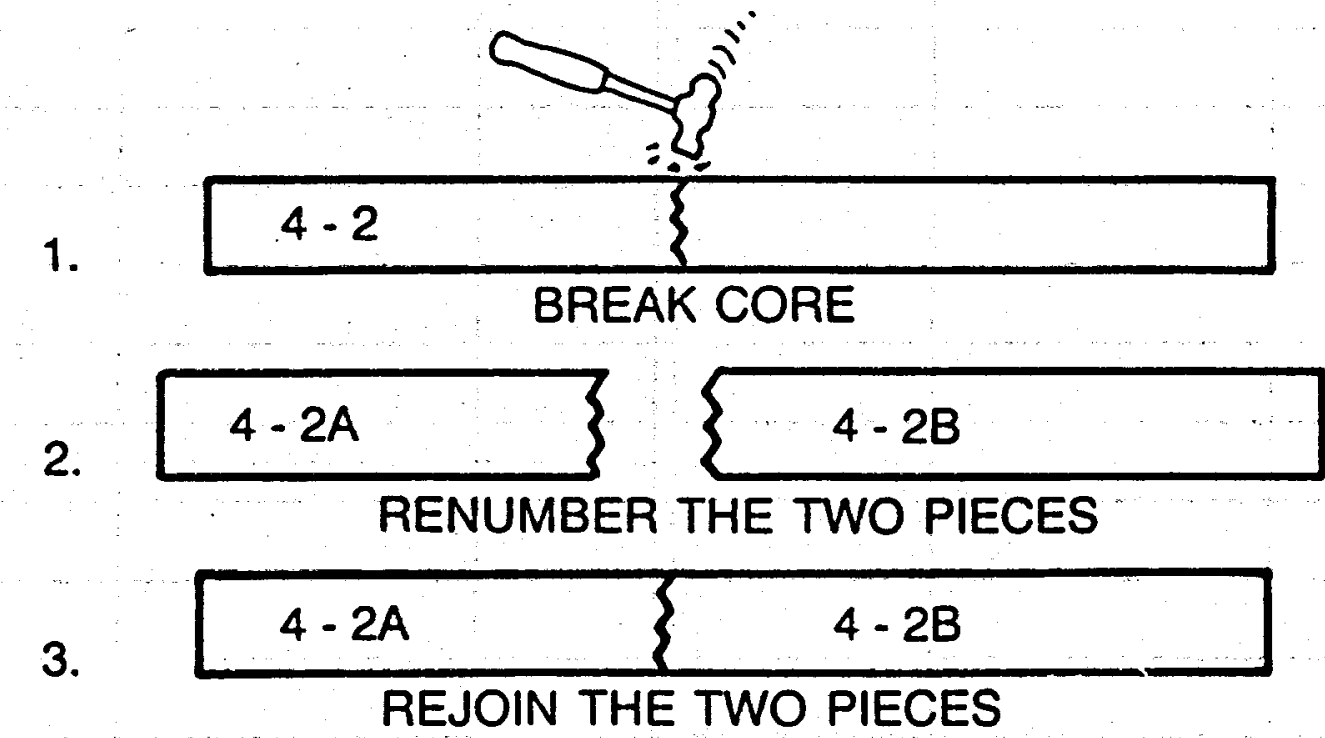

Fig. 4. Procedure to be used when core must be broken.

\section{SAMPLE WRAPPING AND WAXING}

Immediately after the core has been marked and boxed, select an appropriate length for wrapping and waxing, depending on the science plan for the project. Wrap the sample in heavy foil and then tape it with yellow tape along the seam; repeat the depth interval and the original markings from the piece of core on the tape (including the continuous line with downhole arrows and piece number). This information should be legible even after coating the entire package with wax. If it is not, affix another strip of tape to the outside of the wax for identification. After the sample is wrapped and marked, dip it in melted wax (usually pure beeswax) at least twice. Replace wrapped and waxed samples at the proper depth location in the transporting and storage box. Appropriately document intervals wrapped and waxed on the core $\log$ (Fig. 1) as well as on the waxed sampling record (Fig. 5). 
Borehole

Run \#__ to

Page of

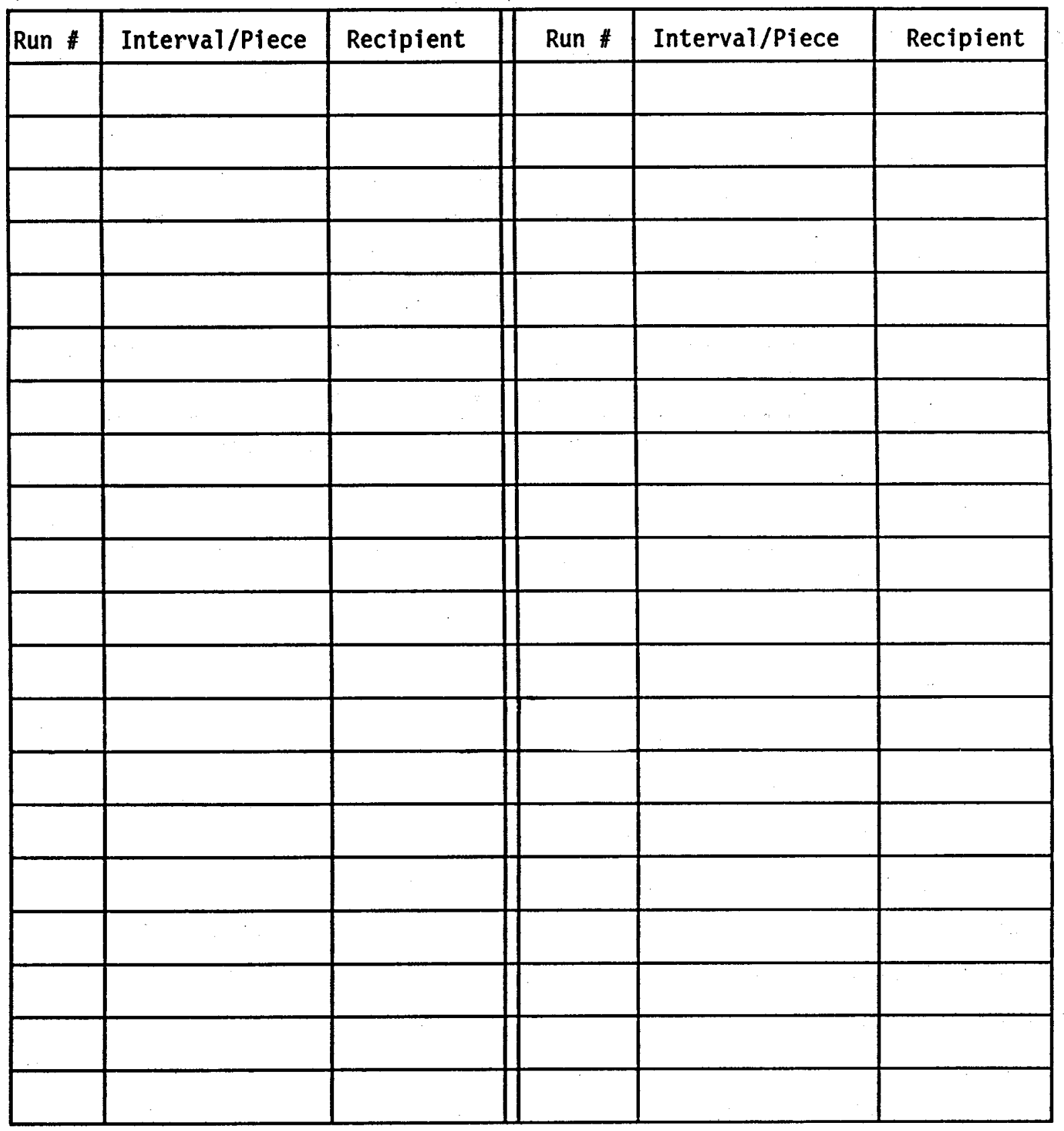

Fig. 5. Record of waxed sample form.

8 


\section{EXTRA CORE (E-CORE) PROCEDURES}

Extra core or E-Core occurs when more core (greater footage) is recovered than was drilled on a particular core run. This occurs because some of the core from a previous core run was not removed but was left at the bottom of the hole. The length of core left in the hole is then recovered on the next core run.

The following procedures should be used when dealing with E-Core:

A. Subtract the amount drilled from the amount recovered to determine the amount of $E$ Core.

B. The E-Core will occur at the top of the core run. Mark it in the following manner:

1. Knowing the length of the E-Core, measure down that distance from the top of the run and draw a line circumferentially around the core at that point.

2. Using a blue felt-tip marker, make a stripe down the length of the E-Core.

3. Mark the run number and piece numbers from the current run on the E-Core.

4. Mark the starting footage of the core on all pieces of the E-Core.

C. Record all information on the core log.

\section{$X$. ON-SITE DRILL CUTTINGS--HANDLING PROCEDURES}

If the borehole is not being continuously cored, it is essential that bit cuttings be collected. The well-site geoscientist is responsible for collecting and processing cuttings at designated depth intervals during periods of rotary drilling. At the INYO-4 site, in the absence of core, cuttings samples should be collected at 10-ft intervals. A sample consists of two 16-0z cups filled with cuttings and capped individually. The contents of one cup should be washed. The well-site geoscientist's responsibilities include labeling cutting samples with hole hame (i.e., INYO-4), depth interval, and a "W" if washed and filling out the bit cuttings log (Fig. 6). Containers should be placed in a handling box for on-site storage and transportation to the repository at Grand Junction, Colorado, for archiving. 
Borehole

Geoscientist

Date

Page _ of

\begin{tabular}{|l|l|l|l|l|}
\hline $\begin{array}{l}\text { Depth or } \\
\text { Depth } \\
\text { Interval }\end{array}$ & $\begin{array}{c}\text { Amount } \\
\text { Recovered } \\
\text { (no. of cups } \\
\text { and/or bags } \\
\text { collected) }\end{array}$ & $\begin{array}{c}\text { Sample Splits } \\
\text { Amount, Reques tor, Org }\end{array}$ & Lithology & Comments \\
\hline & & & & \\
\hline & & & & \\
\hline & & & & \\
\hline & & & & \\
\hline & & & & \\
\hline & & & & \\
\hline & & & & \\
\hline & & & & \\
\hline
\end{tabular}

Fig. 6. Bit cuttings log form. 


\section{CORE AND CUTTINGS--SAMPLE DISTRIBUTION PROCEDURES}

Detailed lithologic descriptions of the core must be completed and photographs of the core must be taken before subsampling. The amount of subsample that a Collaborating Investigator or other scientist can receive will be consistent with the amount specified in the proposal detailing the research being done.

After drilling is complete, core sample splits or subsamples will be distributed to Collaborating Investigators. Following the DOE General Guidelines (Goff 1986), the Chief Scientist will distribute INYO-4 subsamples from Mammoth Lakes and will ship the remaining sample inventory to the repository in Grand Junction, Colorado. The curator of the facility will then assume responsibility for sample distribution and return. Inquiries on the availability of samples can be addressed to

DOE Core and Sample Repository

Grand Junction Projects Office

P.O. Box 2567

Grand Junction, CO 81502-1569

Attention: R. D. Dayvault

Telephone (303) 242-8621, Ext. 535.

\section{ACKNOWLEDGMENTS}

Jamie Gardner and Larry Maassen were particularly helpful in their advice and assistance in preparing this document.

\section{REFERENCE}

Goff, S., 1986, "Curatorial Policy Guidelines and Procedures for the Continental Scientific Drilling Program," Los Alamos National Laboratory report LA-10542-OBES, 23 pp. 


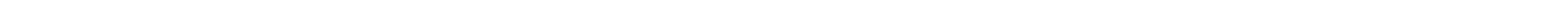



